\title{
Retração total e penetração de cloretos em concretos com cimento Portland branco e escória de alto forno
}

Total shrinkage and chloride ion penetration in concretes made with white Portland cement and blast furnace slag

\author{
Luciano de Medeiros Dellinghausen \\ Antônio Luiz Guerra Gastaldini \\ Geraldo Cechella Isaia \\ Karina Kozoroski Veiga
}

Luciano de Medeiros Dellinghausen Departamento de Estruturas e Construção Civil, Centro de Tecnologia Universidade Federal de Santa Maria RS 509 km 9, Camobi Santa Maria - RS - Brasil CEP 97105-900 Tel.: (55) 3220-8144 E-mail: Imd11@terra.com.br

Antônio Luiz Guerra Gastaldini Departamento de Estruturas e Construção Civil, Centro de Tecnologia Universidade Federal de Santa Maria E-mail: gastaldini@terra.com.br

Geraldo Cechella Isaia Departamento de Estruturas e Construção Civil, Centro de Tecnologia Universidade Federal de Santa Maria

E-mail: gisaia@terra.com.br

Karina Kozoroski Veiga Departamento de Estruturas e Construção Civil, Centro de Tecnologia Universidade Federal de Santa Maria

E-mail: kkveiga@gmail.com

Recebido em 14/07/09 Aceito em 09/12/09

\section{Resumo

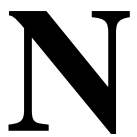

este trabalho foram investigadas as influências do teor de escória e do período de cura na retração total, na penetração de íons cloretos e na resistência à compressão axial de concretos com cimento Portland de alta resistência inicial e cimento Portland branco estrutural. Adotaramse relações água/aglomerante de $0.30,0.42$ e 0.55 , teores de escória, em substituição ao cimento Portland, de $0 \%, 50 \%$ e $70 \%$, e períodos de cura de 3 e 7 dias. Foi empregada uma mistura com $50 \%$ de escória em substituição ao cimento Portland branco, ativada por sulfato de sódio (4\% da massa de aglomerante) para analisar a influência do ativador nas propriedades investigadas. Antes de serem imersos em solução salina os corpos-de-prova foram submetidos a um período de secagem de 91 dias. Dos resultados obtidos, constatou-se que o aumento do teor de escória resultou em decréscimo nos valores de resistência à compressão, de retração e de penetração de cloretos para os dois cimentos investigados. A diminuição no período de cura resultou em maiores valores de retração e de penetração de cloretos, tanto no concreto branco quanto no cinza, independentemente do teor de escória utilizado.

Palavras-chave: Retração. Cimento Portland branco. Escória de alto forno. Cura. Cloretos.

\section{Abstract}

The aim of this study was to investigate the influence of the cement replacement content by slag as well the duration of curing on total shrinkage, chloride ion penetration and compressive strength of concretes made with high early-age strength cement and white Portland cement. Water-binder ratios of 0.30, 0.42 and 0.55 , curing duration of 3 and 7 days, and cement replacement contents of $0 \%$, $50 \%$ and $70 \%$ were investigated. In order to analyze the influence of the alkali activation on the properties investigated, a concrete made with $50 \%$ white Portland cement replacement content by slag and activated by sodium sulfate (4\% of binder mass) was used. Before being immersed in the chloride solution, the specimens were subjected to a drying period of 91 days. The results obtained revealed that an increase in the slag content decreased the compressive strength and the drying shrinkage values, as well as the depth of chloride penetration in both cements. Reducing the curing duration resulted in greater drying shrinkage and depth of chloride penetration for both cements, regardless of the slag content.

Keywords: Shrinkage. White Portland cement. Blast furnace slag. Curing. Chlorides. 


\section{Introdução}

O consumo universal e crescente do concreto e, consequentemente, seu impacto no meio ambiente têm conscientizado o meio técnico quanto à necessidade de racionalidade e de sustentabilidade no uso das matérias-primas constituintes, evitandose, assim, o desperdício delas e da energia envolvida no processo de produção do concreto como um todo. Ratifica essa preocupação o fato de que, segundo Mehta e Monteiro (2008), cada tonelada de cimento produzida gera outra tonelada de $\mathrm{CO}_{2}$ liberado na atmosfera durante seu processo de fabricação. Acrescem-se a isso, por vezes, a deterioração precoce e a redução da vida útil das estruturas, gerando gastos com manutenção e reposição, o que demanda matéria-prima e resíduos de construções.

A redução do consumo de cimento por metro cúbico de concreto é uma prática bastante difundida e visa à diminuição da quantia de gases poluentes liberados durante a fabricação do cimento, além da economia no consumo de energia (JOHN, 1995). Para tanto, faz-se uso de subprodutos industriais como a escória de altoforno, na forma de substituição parcial de seu conteúdo, sendo utilizada juntamente com o cimento Portland como material aglomerante. O uso da escória é bastante benéfico para o concreto, porque promove um refinamento dos poros (NAKAMURA et al., 1992), aumenta a resistividade elétrica (WEE et al., 2000) e diminui sua suscetibilidade à penetração de alguns tipos de agentes agressivos que possam atacar a armadura, como o íon cloreto, por exemplo (ALDEA et al., 2000; LUO et al., 2003; MOHAMMED et al., 2002; ZHANG et al., 1999), o agente agressivo mais comum e considerado a maior causa de corrosão prematura das armaduras (ACI COMMITTEE 222, 2001), afetando sua integridade e durabilidade.

A versatilidade cromática e a valorização da estrutura como elemento estético são as razões pelas quais alguns projetistas têm especificado o concreto branco em suas obras. Contudo, esses concretos necessitam de processos de produção e de controle de qualidade diferenciados, que, somados ao custo do cimento branco, quase três vezes o do cinza (NEVILLE, 1997), resulta em custos das estruturas superiores àqueles obtidos quando se utiliza o cimento cinza. Assim, a substituição parcial do cimento branco por escória, adição mineral de brancura similar, é uma forma de reduzir o custo do material e de contribuir para o incremento em sua utilização.

Tazawa et al. (1989) e Sakai et al. (1992) empregaram escória em substituição parcial ao cimento Portland comum e comprovaram essa prática de grande valia na redução da magnitude da retração hidráulica, a qual ocorre devido à perda de umidade no concreto. Esse fenômeno pode reduzir a durabilidade da estrutura, pois um elemento de concreto com restrição de deformação por retração pode desenvolver tensões que levem à formação de fissuras, através das quais agentes agressivos podem penetrar e causar algum dano à armadura, reduzindo sua vida útil. Suzuki et al. (1993) enfatizam que a fissuração por retração hidráulica não é influenciada apenas pela quantia de retração, mas também pelo módulo de elasticidade, pela fluência e pela resistência à tração do concreto.

A influência da composição química do cimento (ACI COMMITTEE 209, 2005), das condições de temperatura e umidade (CHERN; CHAN, 1989), da temperatura elevada de cura (BAKHAREV et $a l ., 1999$ ) e de ativadores químicos (ATIS et al. 2009; MUN et al., 2007) foram pesquisadas em concretos compostos com cimento cinza e escória ou somente com escória (concretos de escória ativada). Contudo, poucos trabalhos têm sido publicados a respeito da retração de concreto composto com cimento Portland branco e escória de alto-forno.

Neste trabalho a escória de alto-forno foi utilizada em substituição parcial do cimento Portland branco e cinza na produção de concretos com diferentes relações entre água e aglomerante (a/agl). Com o intuito de acelerar as reações de hidratação, fez-se uso de ativador químico. Este trabalho apresenta a influência do período de cura na retração total dos concretos empregados, bem como na resistência à compressão axial e à penetração de cloretos após a retração.

\section{Programa experimental}

\section{Materiais}

Foram utilizados o cimento Portland branco (CPB40), o cimento Portland de alta resistência inicial (CPV-ARI) e a escória de alto-forno, proveniente da indústria siderúrgica nacional. As características físicas e químicas dos aglomerantes são apresentadas na Tabela 1. 


\begin{tabular}{|c|c|c|c|}
\hline \multirow{2}{*}{ Componentes } & \multicolumn{3}{|c|}{ Porcentagem em massa dos materiais (\%) } \\
\hline & CPV-ARI & CPB-40 & Escória \\
\hline Perda ao fogo & 3,17 & 11,60 & - \\
\hline $\mathrm{SiO}_{2}$ & 19,34 & 17,95 & 33,84 \\
\hline $\mathbf{A l}_{2} \mathbf{O}_{3}$ & 4,55 & 2,98 & 10,35 \\
\hline $\mathrm{Fe}_{2} \mathrm{O}_{3}$ & 2,77 & 0,21 & 0,67 \\
\hline $\mathrm{CaO}$ & 62,43 & 59,40 & 44,50 \\
\hline MgO & 2,61 & 2,87 & 7,99 \\
\hline $\mathrm{SO}_{3}$ & 2,89 & 3,09 & - \\
\hline $\mathbf{S}$ & - & - & 0,83 \\
\hline $\mathrm{Na}_{2} \mathrm{O}$ & 0,09 & 0,43 & 0,20 \\
\hline $\mathbf{K}_{2} \mathbf{O}$ & 0,74 & 0,36 & 0,40 \\
\hline Início de pega & $125 \mathrm{~min}$ & $100 \mathrm{~min}$ & - \\
\hline $\begin{array}{c}\text { Massa específica } \\
\left(\mathrm{g} / \mathrm{cm}^{3}\right)\end{array}$ & 3,11 & 2,97 & 2,92 \\
\hline $\begin{array}{c}\text { Área específica } \\
\text { Blaine }\left(\mathrm{cm}^{2} / \mathbf{g}\right)\end{array}$ & 4.490 & 5.070 & 4.090 \\
\hline $\begin{array}{c}\text { Resíduo na \# 0,075 } \\
\text { mm (\%) }\end{array}$ & 0,13 & 0,29 & - \\
\hline
\end{tabular}

Tabela 1 - Características físicas e químicas dos aglomerantes

O agregado miúdo empregado foi a areia natural, que apresentou módulo de finura de 2,45 , massa específica de $2,63 \mathrm{~kg} / \mathrm{dm}^{3}$ e massa unitária de 1,66 $\mathrm{kg} / \mathrm{dm}^{3}$. O agregado graúdo usado foi a pedra britada, de rocha de origem diabásica, com módulo de finura de 6,87 , massa específica de $2,49 \mathrm{~kg} / \mathrm{dm}^{3}$ e massa unitária de $1,40 \mathrm{~kg} / \mathrm{dm}^{3}$. Ambos os agregados foram lavados para remoção de impurezas e secos para remoção de umidade.

Utilizou-se um aditivo superplastificante de terceira geração, à base de éter policarboxílico modificado, quando necessário, para a obtenção de consistências prefixadas em $90 \mathrm{~mm} \pm 10 \mathrm{~mm}$.

$\mathrm{O}$ ativador químico empregado foi o sulfato de sódio $\left(\mathrm{Na}_{2} \mathrm{SO}_{4}\right)$, disponível comercialmente, em teor de $4 \%$ da massa de aglomerante, definido em trabalhos anteriores (GOMES, 2003; GASTALDINI et al., 2007; SCHENEIDER et al., 2008).

A seguir são apresentados os resultados do ensaio de índice de brancura (\%) realizado em pasta para as misturas com CPB-40 e escória de alto-forno (EAF). O índice mínimo satisfatório exigido pela NBR NM 3 (2000) é de 78\%: 100\% CPB = 82,16; $100 \% \mathrm{EAF}=77,13 ; 50 \% \mathrm{CPB}+50 \% \mathrm{EAF}=$ 79,$76 ; 30 \% \mathrm{CPB}+70 \% \mathrm{EAF}=78,59$

\section{Misturas empregadas}

Foram preparadas, a partir dos dois cimentos empregados, as misturas de referência branca e cinza (compostas de $100 \%$ de cimento Portland como material aglomerante, chamadas REF CPB e REF CPV), e outras quatro, constituídas de $50 \%$ e $70 \%$ de escória como substituto parcial dos cimentos branco e cinza (50E CPB e 70E CPB, 50E CPV e 70E CPV respectivamente). Uma mistura com substituição de $50 \%$ de escória e adição de $4 \%$ (da massa de aglomerante) de ativador químico $\left(\mathrm{Na}_{2} \mathrm{SO}_{4}\right)$ foi preparada com CPB-40 (50A CPB). Para todas as misturas foram adotadas três relações a/agl $(0,30 ; 0,42$ e 0,55$)$ e teor de argamassa de $52 \%$ em massa de materiais secos. Não foram constatadas diferenças substanciais de trabalhabilidade ao se compararem os concretos branco e cinza entre si. Segundo o ACI Committee 233 (2005), a substituição parcial do cimento pela escória melhora a trabalhabilidade do concreto. Observa-se na Tabela 2 que ocorreu diminuição do teor de aditivo nas misturas com escória, exceto para a mistura com ativador químico (50A CPB) na relação a/agl 0,30. Nas misturas com escória fez-se uma correção na quantidade de areia para manter o mesmo teor de argamassa da mistura de referência, devido à menor massa específica da escória em relação ao cimento. A Tabela 2 apresenta o consumo de materiais por metro cúbico de concreto. 


\begin{tabular}{|c|c|c|c|c|c|c|c|c|}
\hline \multirow{2}{*}{ Mistura } & \multirow{2}{*}{$\mathbf{a} / \mathbf{a g l}$} & \multicolumn{7}{|c|}{ Materiais $\left(\mathrm{kg} / \mathrm{m}^{3}\right.$ de concreto) } \\
\hline & & Cimento & Escória & Areia & Brita & Aditivo $^{1}$ & Ativador & Água $^{2}$ \\
\hline \multirow{3}{*}{ REF CPB } & 0,30 & 516,7 & - & 640,7 & $1.064,3$ & 1,70 & - & 153,8 \\
\hline & 0,42 & 415,4 & - & 706,2 & $1.038,6$ & 0,33 & - & 174,3 \\
\hline & 0,55 & 305,0 & - & 820,4 & $1.039,9$ & - & - & 167,7 \\
\hline \multirow{3}{*}{ REF CPV } & 0,30 & 520,7 & - & 645,7 & $1.072,7$ & 1,72 & - & 155,0 \\
\hline & 0,42 & 418,1 & - & 710,7 & $1.045,2$ & 0,33 & - & 175,4 \\
\hline & 0,55 & 306,4 & - & 824,2 & $1.044,8$ & - & - & 168,5 \\
\hline \multirow{3}{*}{ 50E CPB } & 0,30 & 260,0 & 260,0 & 624,0 & $1.071,2$ & 1,46 & - & 155,0 \\
\hline & 0,42 & 208,5 & 208,5 & 696,2 & $1.042,3$ & 0,27 & - & 174,9 \\
\hline & 0,55 & 152,9 & 152,9 & 813,3 & $1.042,7$ & - & - & 168,2 \\
\hline \multirow{3}{*}{ 50E CPV } & 0,30 & 261,0 & 261,0 & 626,4 & $1.075,4$ & 1,46 & - & 155,6 \\
\hline & 0,42 & 209,1 & 209,1 & 698,4 & $1.045,6$ & 0,27 & - & 175,5 \\
\hline & 0,55 & 153,2 & 153,2 & 815,2 & $1.045,1$ & - & - & 168,6 \\
\hline \multirow{3}{*}{ 70E CPB } & 0,30 & 156,2 & 364,5 & 619,6 & $1.072,6$ & 1,46 & - & 155,2 \\
\hline & 0,42 & 125,2 & 292,2 & 692,8 & $1.043,4$ & 0,29 & - & 175,1 \\
\hline & 0,55 & 91,8 & 214,2 & 810,9 & $1.043,5$ & - & - & 168,3 \\
\hline \multirow{3}{*}{ 70E CPV } & 0,30 & 156,6 & 365,4 & 621,1 & $1.075,2$ & 1,46 & - & 155,6 \\
\hline & 0,42 & 125,5 & 292,7 & 694,2 & $1.045,4$ & 0,29 & - & 175,4 \\
\hline & 0,55 & 91,9 & 214,5 & 812,1 & $1.045,0$ & - & - & 168,5 \\
\hline \multirow{3}{*}{ 50A CPB } & 0,30 & 260,0 & 260,0 & 624,0 & $1.071,2$ & 5,25 & 20,80 & 152,3 \\
\hline & 0,42 & 208,5 & 208,5 & 696,2 & $1.042,3$ & 0,13 & 16,68 & 175,0 \\
\hline & 0,55 & 152,9 & 152,9 & 813,3 & $1.042,7$ & - & 12,23 & 168,2 \\
\hline
\end{tabular}

${ }^{1}$ Valor correspondente à massa total do aditivo ( $30 \%$ de fase sólida $+70 \%$ de fase líquida)

2 Água presente no aditivo descontada do total de água da mistura correspondente

Tabela 2 - Consumo de materiais por metro cúbico de concreto

\section{Ensaios experimentais}

\section{Retração total}

Este ensaio foi realizado conforme recomendações da ASTM C-157 (ASTM, 2006) e ASTM C-490 (ASTM, 2004). Para cada mistura investigada foram moldados quatro corpos de prova de dimensões $100 \mathrm{~mm}$ x $100 \mathrm{~mm}$ x $285 \mathrm{~mm}$, desmoldados após $24 \mathrm{~h}$ e conservados em câmara úmida, temperatura de $23 \pm 2{ }^{\circ} \mathrm{C}$ e umidade relativa maior do que $95 \%$, durante os prazos de cura de 3 e 7 dias. Nessas idades fez-se a primeira leitura de seus comprimentos. Na sequência, os corpos de prova foram mantidos em sala climatizada (temperatura $=23 \pm 2{ }^{\circ} \mathrm{C}$ e UR $=50 \pm 10 \%$ ) para secagem ao ar. As leituras de retração foram feitas nas idades de 7, 14, 21, 28, 35, 56, 91 e 182 dias após a retirada da câmara úmida. Essas leituras foram realizadas em comparador de expansibilidade com marcador digital de precisão $0,001 \mathrm{~mm}$.

\section{Penetração de cloretos por imersão}

Inicialmente foram moldados corpos de prova prismáticos de dimensões $100 \mathrm{~mm}$ x $100 \mathrm{~mm} \mathrm{x}$ $285 \mathrm{~mm}$, que foram conservados em câmara úmida por período de 3 e 7 dias, e depois mantidos em sala climatizada (temperatura $=23 \pm 2{ }^{\circ} \mathrm{C}$ e UR $=$ $50 \pm 10 \%$ ) durante 91 dias. Nessa idade, os corpos de prova foram cortados, obtendo-se amostras de dimensões $100 \mathrm{~mm} \times 100 \mathrm{~mm} \times 53 \mathrm{~mm}$, as quais foram impermeabilizadas em quatro de suas seis faces com três demãos de verniz poliuretânico, permitindo, assim, a penetração de íons cloretos somente nas duas faces laterais $(100 \mathrm{~mm}$ x 53 $\mathrm{mm})$. Após a preparação, as amostras foram imersas num reservatório com solução salina na proporção de $31,94 \mathrm{~g}$ de $\mathrm{NaCl}$ para cada litro de água destilada, conforme procedimento proposto por Wee et al. (2000). 
Nas idades de ensaio (7, 14, 28, 56 e 91 dias), as amostras (quatro para cada idade) foram lavadas com água potável e rompidas na direção de penetração dos íons cloretos. Em seguida, foi aspergida solução de nitrato de prata $(17 \mathrm{~g}$ de $\mathrm{AgNO}_{3}$ para cada litro de água deionizada) para percepção visual da região de penetração de íons cloretos e registro fotográfico após a secagem da solução sobre a face rompida. Através de inserção da fotografia digitalizada no programa computacional AutoCAD, foi possível colocar a imagem em escala e sobre ela traçar um contorno ao redor da região penetrada. Essa região foi dividida por linhas paralelas traçadas ao longo da profundidade de penetração e espaçadas $1 \mathrm{~mm}$ uma da outra; através de uma rotina chamada
COTA, foi medido o comprimento de cada uma dessas linhas. Essa rotina gerou automaticamente um arquivo em formato Excel (Microsoft), do qual se obtiveram os valores, que depois foram transferidos para uma planilha onde foi realizado um tratamento estatístico e obtida a distância média de penetração de íons cloretos.

\section{Resistência à compressão axial}

Este ensaio foi realizado conforme a NBR 5739:2007. Para cada uma das misturas investigadas, foram moldados quatro corpos de prova cilíndricos $(\varnothing 100 \mathrm{~mm}$ x $200 \mathrm{~mm})$ para cada uma das idades de cura, 3, 7, 28 e 91 dias.

\begin{tabular}{|c|c|c|c|c|c|c|c|c|c|}
\hline \multirow{2}{*}{$\begin{array}{c}\text { Cura 3D } \\
\text { Mistura }\end{array}$} & \multirow{2}{*}{$\mathbf{a} / \mathbf{a g l}$} & \multicolumn{8}{|c|}{ 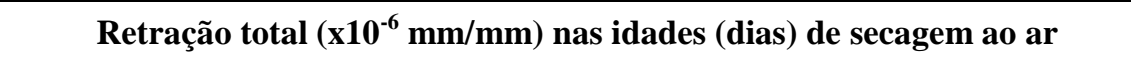 } \\
\hline & & 7 & 14 & 21 & 28 & 35 & 56 & 91 & 182 \\
\hline \multirow{3}{*}{ REF CPB } & 0,30 & 455 & 527 & 581 & 633 & 719 & 747 & 757 & 774 \\
\hline & 0,42 & 386 & 450 & 498 & 540 & 639 & 658 & 681 & 724 \\
\hline & 0,55 & 366 & 426 & 477 & 534 & 641 & 679 & 701 & 778 \\
\hline \multirow{3}{*}{ REF CPV } & 0,30 & 247 & 301 & 328 & 344 & 361 & 461 & 487 & 490 \\
\hline & 0,42 & 256 & 315 & 345 & 368 & 401 & 483 & 497 & 572 \\
\hline & 0,55 & 239 & 284 & 317 & 345 & 390 & 476 & 508 & 568 \\
\hline \multirow{3}{*}{ 50E CPB } & 0,30 & 355 & 424 & 448 & 463 & 476 & 521 & 547 & 594 \\
\hline & 0,42 & 281 & 327 & 370 & 402 & 416 & 477 & 498 & 572 \\
\hline & 0,55 & 204 & 250 & 296 & 329 & 353 & 417 & 449 & 536 \\
\hline \multirow{3}{*}{ 50E CPV } & 0,30 & 336 & 399 & 428 & 448 & 467 & 489 & 516 & 594 \\
\hline & 0,42 & 278 & 337 & 364 & 378 & 392 & 433 & 484 & 566 \\
\hline & 0,55 & 253 & 293 & 319 & 342 & 361 & 442 & 494 & 520 \\
\hline \multirow{3}{*}{ 70Е СРВ } & 0,30 & 135 & 197 & 272 & 289 & 304 & 323 & 395 & 472 \\
\hline & 0,42 & 66 & 138 & 218 & 245 & 266 & 299 & 388 & 474 \\
\hline & 0,55 & 30 & 76 & 177 & 207 & 230 & 277 & 364 & 466 \\
\hline \multirow{3}{*}{ 70E CPV } & 0,30 & 147 & 236 & 269 & 292 & 308 & 367 & 405 & 462 \\
\hline & 0,42 & 163 & 262 & 302 & 333 & 351 & 440 & 510 & 558 \\
\hline & 0,55 & 189 & 319 & 372 & 407 & 440 & 500 & 563 & 656 \\
\hline \multirow{3}{*}{ 50A CPB } & 0,30 & 132 & 220 & 265 & 317 & 323 & 365 & 464 & 480 \\
\hline & 0,42 & 133 & 235 & 296 & 347 & 371 & 440 & 536 & 562 \\
\hline & 0,55 & 59 & 153 & 174 & 246 & 266 & 333 & 459 & 464 \\
\hline
\end{tabular}

Tabela 3 - Microdeformações para os concretos com cura de 3 dias 


\begin{tabular}{|c|c|c|c|c|c|c|c|c|c|}
\hline \multirow{2}{*}{$\begin{array}{l}\text { Cura 7D } \\
\text { Mistura } \\
\end{array}$} & \multirow{2}{*}{ a/agl } & \multicolumn{8}{|c|}{ Retração total $\left(\times 10^{-6} \mathrm{~mm} / \mathrm{mm}\right)$ nas idades (dias) de secagem ao ar } \\
\hline & & 7 & 14 & 21 & 28 & 35 & 56 & 91 & 182 \\
\hline \multirow{3}{*}{ REF CPB } & 0,30 & 336 & 389 & 433 & 460 & 509 & 540 & 609 & 612 \\
\hline & 0,42 & 321 & 373 & 419 & 434 & 501 & 589 & 639 & 680 \\
\hline & 0,55 & 328 & 385 & 429 & 459 & 505 & 591 & 631 & 706 \\
\hline \multirow{3}{*}{ REF CPV } & 0,30 & 294 & 353 & 379 & 401 & 421 & 446 & 523 & 538 \\
\hline & 0,42 & 327 & 407 & 440 & 471 & 496 & 530 & 616 & 660 \\
\hline & 0,55 & 245 & 297 & 391 & 429 & 438 & 448 & 477 & 550 \\
\hline \multirow{3}{*}{ 50E CPB } & 0,30 & 204 & 268 & 305 & 341 & 364 & 421 & 425 & 506 \\
\hline & 0,42 & 209 & 259 & 321 & 366 & 398 & 453 & 491 & 560 \\
\hline & 0,55 & 168 & 217 & 253 & 294 & 337 & 406 & 433 & 576 \\
\hline \multirow{3}{*}{ 50E CPV } & 0,30 & 239 & 283 & 316 & 349 & 399 & 409 & 472 & 472 \\
\hline & 0,42 & 257 & 309 & 344 & 383 & 446 & 483 & 549 & 558 \\
\hline & 0,55 & 221 & 270 & 304 & 340 & 395 & 428 & 511 & 516 \\
\hline \multirow{3}{*}{ 70E CPB } & 0,30 & 149 & 179 & 253 & 264 & 284 & 321 & 331 & 404 \\
\hline & 0,42 & 79 & 105 & 173 & 213 & 219 & 309 & 344 & 544 \\
\hline & 0,55 & 49 & 87 & 110 & 119 & 131 & 201 & 236 & 402 \\
\hline \multirow{3}{*}{ 70E CPV } & 0,30 & 152 & 221 & 261 & 277 & 293 & 321 & 367 & 488 \\
\hline & 0,42 & 118 & 181 & 200 & 214 & 224 & 281 & 332 & 492 \\
\hline & 0,55 & 137 & 209 & 237 & 250 & 265 & 314 & 364 & 574 \\
\hline \multirow{3}{*}{ 50A CPB } & 0,30 & 163 & 215 & 268 & 329 & 345 & 408 & 471 & 488 \\
\hline & 0,42 & 101 & 185 & 287 & 373 & 475 & 569 & 660 & 672 \\
\hline & 0,55 & 37 & 79 & 108 & 175 & 193 & 272 & 385 & 398 \\
\hline
\end{tabular}

Tabela 4 - Microdeformações para os concretos com cura de 7 dias

\section{Análise e discussão dos resultados}

\section{Retração total}

Os resultados do ensaio de retração total são apresentados numericamente nas Tabelas 3 e 4, e graficamente nas Figuras 1 a 4 . Nelas são mostradas as microdeformações $\left(10^{-6} \mathrm{~mm} / \mathrm{mm}\right)$ dos corpos de prova das misturas em cada uma das idades avaliadas para os dois períodos de cura. Constata-se que, em praticamente todas as misturas, a maior parte da redução dimensional ocorreu durante as três primeiras semanas, sendo creditada, principalmente, à perda de parte da água presente devido à cura, além da contribuição da retração autógena. Os valores de retração obtidos situam-se entre aqueles relatados por Zia et al. (1997), para concretos em idades avançadas, entre 200 e $800 \times 10^{-6} \mathrm{~mm} / \mathrm{mm}$.

Conforme o ACI Committee 209 (2005), para concretos de resistências normais/típicas, ou seja, abaixo daquelas dos concretos de alto desempenho, considera-se, geralmente, que a deformação total por retração é devida à retração hidráulica, de forma que qualquer contribuição da retração autógena seja desconsiderada. Desse modo, nesta pesquisa, consideraram-se como referências pesquisas nas quais foi investigada a retração hidráulica de concretos com escória. 


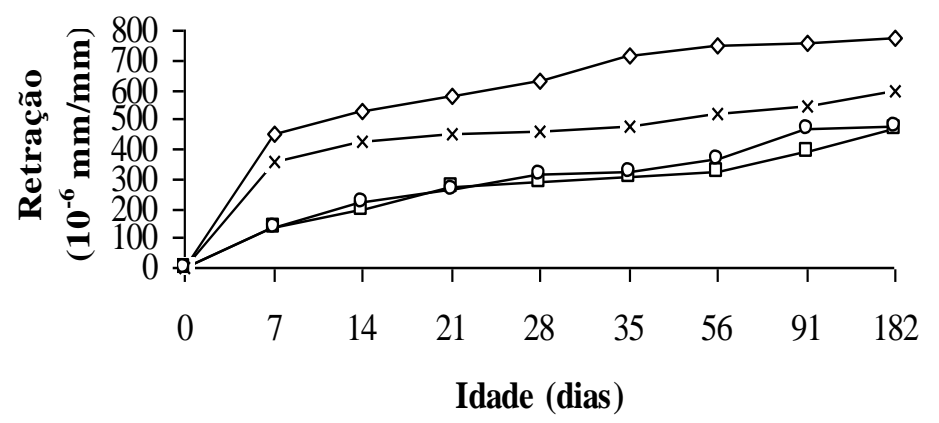

$$
\multimap \text { REF CPB }-x-50 \mathrm{E} \mathrm{CPB} \square-70 \mathrm{E} \mathrm{CPB}-50 \mathrm{~A} \text { CPB }
$$

(a) Cura 3 dias, relação a/agl=0,30

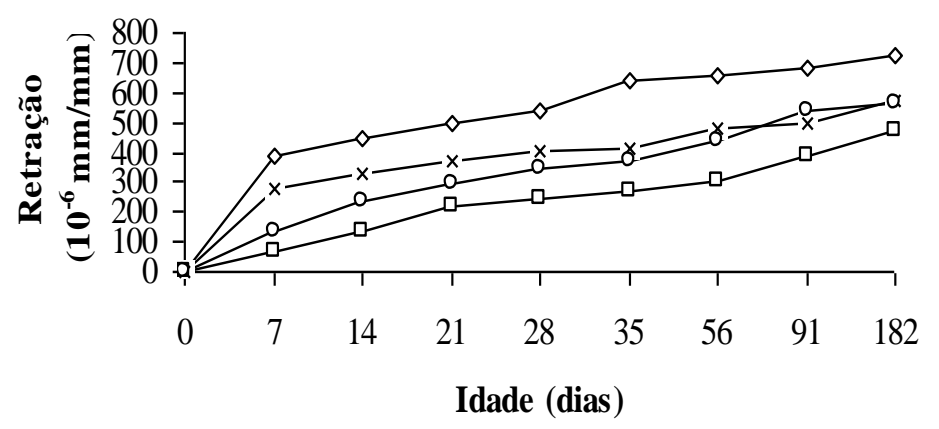

$$
\multimap \text { REF CPB }-x-50 \mathrm{E} \mathrm{CPB}-70 \mathrm{E} \mathrm{CPB}-50 \mathrm{~A} \text { CPB }
$$

(b) Cura 3 dias, relação a/agl=0,42

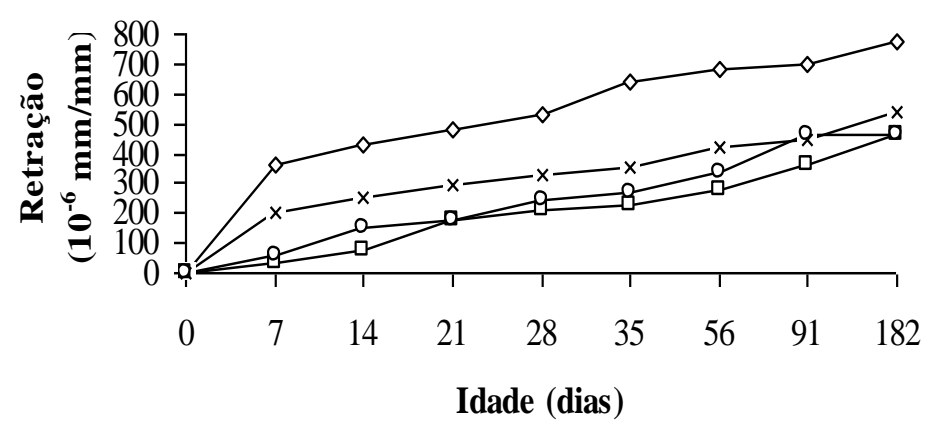

$$
\multimap \text { REF CPB }-x-50 \mathrm{E} \mathrm{CPB}-70 \mathrm{E} \mathrm{CPB} \multimap 50 \mathrm{~A} \mathrm{CPB}
$$

(c) Cura 3 dias relação a/agl=0,55

Figura 1 - Retração dos concretos com CPB, 3 dias de cura 


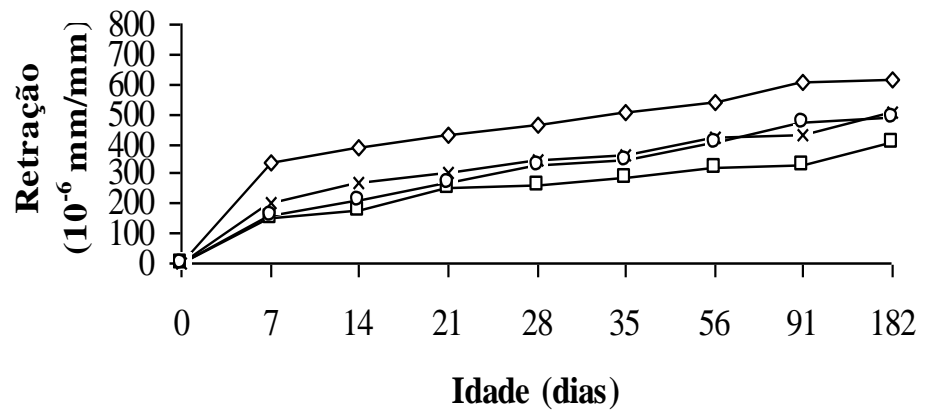

\section{$\multimap$ REF CPB $-x-50 \mathrm{E} \mathrm{CPB}-70 \mathrm{E} \mathrm{CPB}-50 \mathrm{~A}$ CPB}

(a) Cura 7 dias relação a/agl=0,30

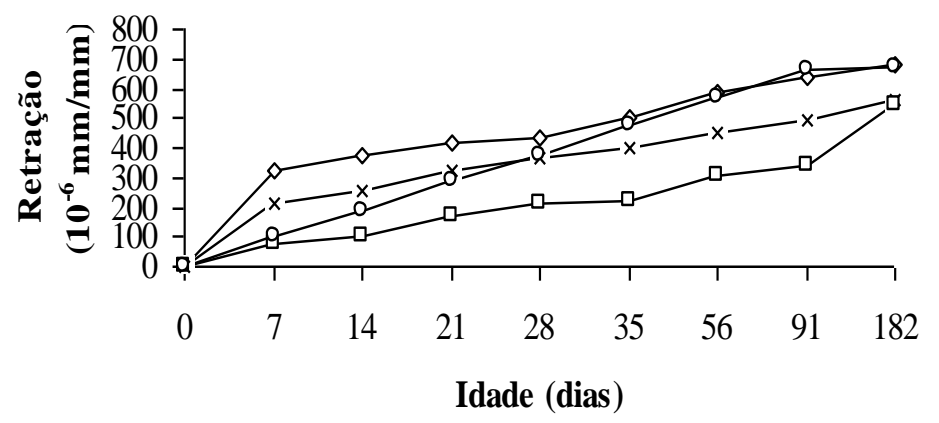

$\multimap$ REF CPB $-x-50 \mathrm{E}$ CPB $\multimap 70 \mathrm{E} \mathrm{CPB} \multimap 50 \mathrm{~A} \mathrm{CPB}$

(b) Cura 7 dias relação a/agl=0,42

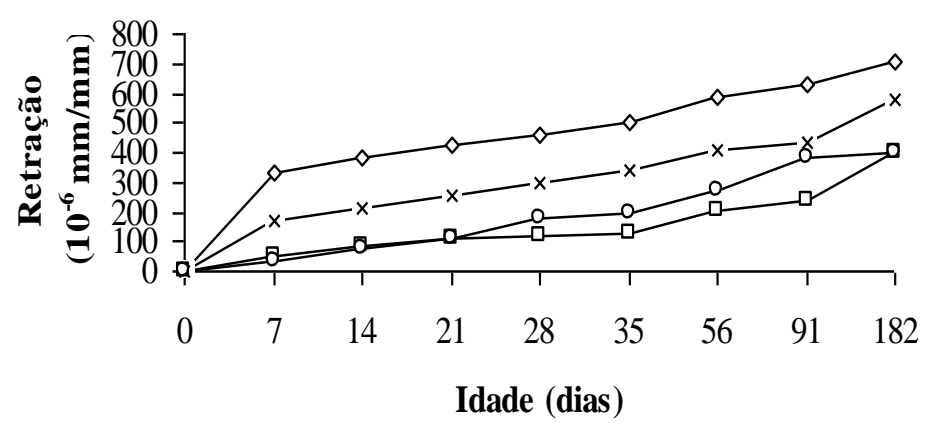

$\multimap$ REF CPB $-x-50 \mathrm{E}$ CPB $-\square-70 \mathrm{E}$ CPB $\multimap-50 \mathrm{~A} \mathrm{CPB}$

(b) Cura 7 dias relação a/agl=0,55

Figura 2 - Retração dos concretos com CPB, 7 dias de cura 


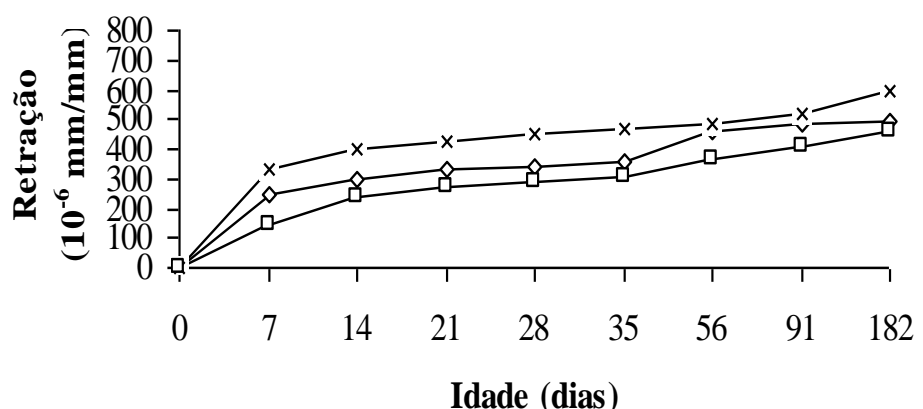

Idade (dias)

$\multimap$ REF CPV $-x-50 \mathrm{E} \mathrm{CPV}-70 \mathrm{E} \mathrm{CPV}$

(a) Cura 3 dias relação a/agl=0,30

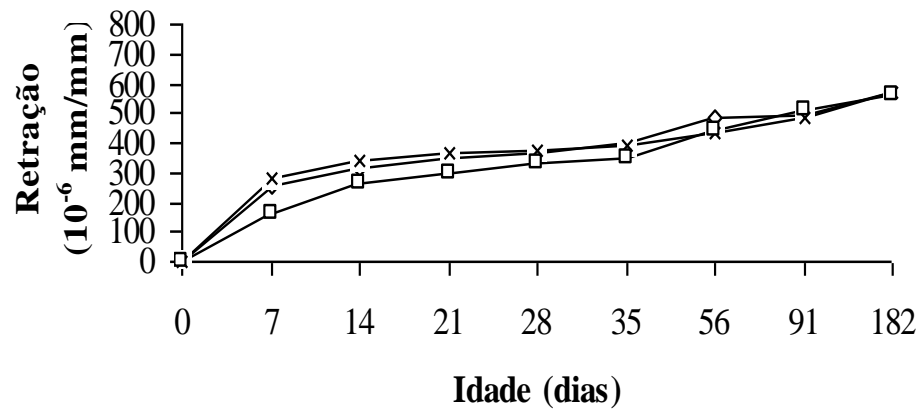

$\multimap$ REF CPV $-x-50 \mathrm{E} \mathrm{CPV}-70 \mathrm{E} \mathrm{CPV}$

(b) Cura 3 dias relação a/agl=0,42

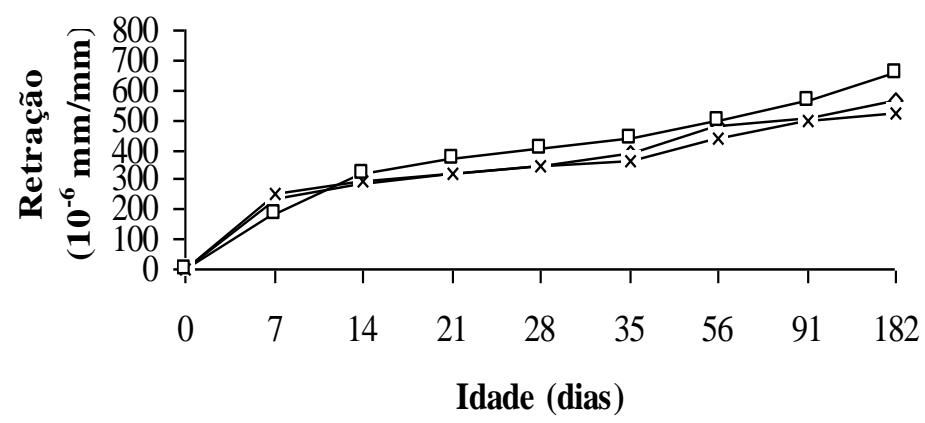

$\leadsto$ REF CPV -x-50E CPV $-\neg 70 \mathrm{E} \mathrm{CPV}$

(c) Cura 3 dias relação a/agl=0,55

Figura 3 - Retração dos concretos com CPV, 3 dias de cura 


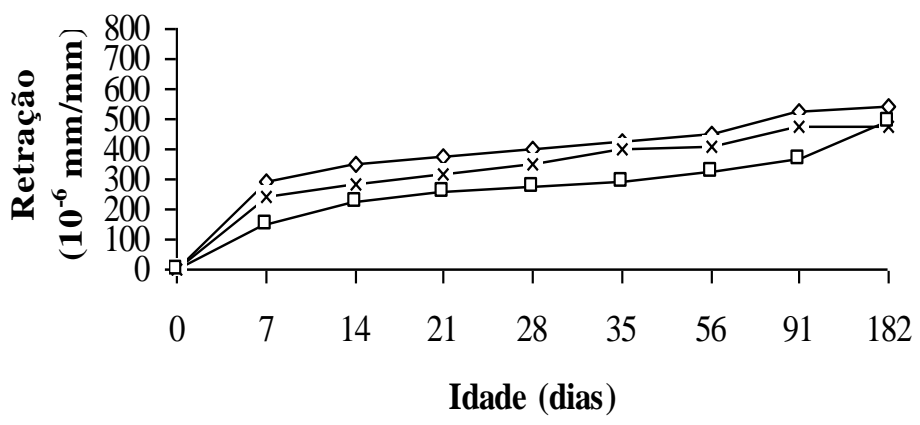

$\multimap$ REF CPV $-x-50 \mathrm{E}$ CPV $\neg-70 \mathrm{E}$ CPV

(a) Cura 7 dias relação a/agl=0,30

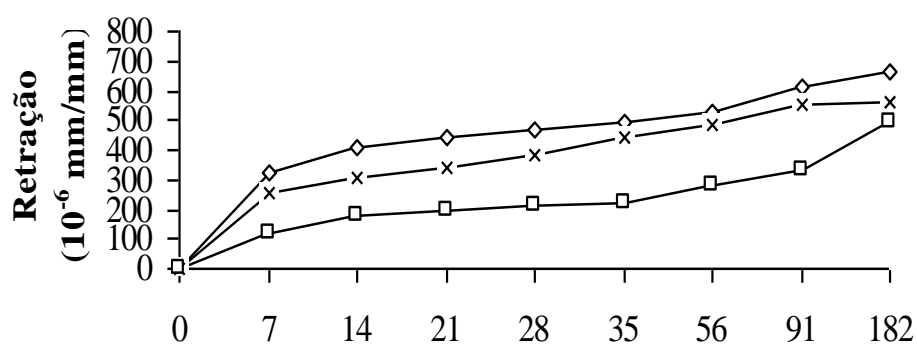

Idade (dias)

$\neg-\mathrm{REF} C \mathrm{PV}-\mathrm{x}-50 \mathrm{E}$ CPV $-\square-70 \mathrm{E}$ CPV

(b) Cura 7 dias relação a/agl=0,42

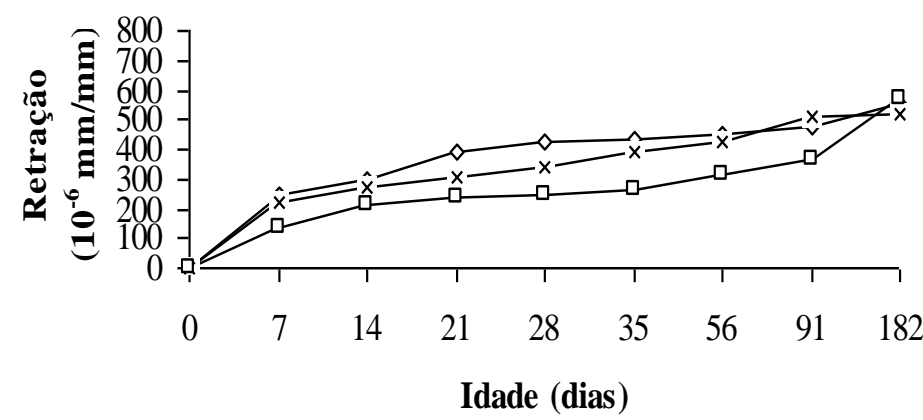

$\multimap-\mathrm{REF} C \mathrm{PV}-\mathrm{x}-50 \mathrm{E}$ CPV $\neg-70 \mathrm{E} \mathrm{CPV}$

(c) Cura 7 dias relação a/agl=0,55

Figura 4 - Retração dos concretos com CPV, 7 dias de cura

Até 182 dias de exposição ao ar, o concreto de referência (REF) branco apresentou maior retração que o correspondente cinza, em igualdade de relação a/agl e prazo de cura.

Comparando-se os teores de escória entre si nos concretos confeccionados com CPB-40, em ambos os prazos de cura, notou-se, no geral, redução pronunciada de retração com o aumento do teor de escória. Já nos concretos moldados com CPV-ARI, de maneira geral e independentemente do prazo de cura, não se constatou diferença de comportamento quanto à retração, quando comparado o concreto de referência com aqueles compostos de escória. Brooks et al. (1992) e Sivasundaram e Malhotra (1992) investigaram misturas compostas com cimento Portland comum e escória e observaram comportamento similar. 
Independentemente do cimento utilizado e da relação a/agl adotada, observa-se retração ligeiramente maior nos concretos curados durante 3 dias, porém as diferenças foram inexpressivas, o que caracterizou similaridade entre os prazos de cura investigados. Não se constataram, de forma generalizada, diferenças expressivas de retração entre as diferentes relações a/agl analisadas em uma mesma mistura. Esse comportamento também foi evidenciado por Sivasundaram e Malhotra (1992).

Segundo Young (1988), a retração hidráulica, em condições usuais, depende da perda de água dos mesoporos (raios dos poros entre as dimensões de $1 \mathrm{~nm}$ e $25 \mathrm{~nm}$ ), de modo que nem sempre o concreto que apresenta maior quantidade de água evaporável é o que retrai mais.

Collins e Sanjayan (2000) pesquisaram o efeito da distribuição dos tamanhos dos poros na retração hidráulica em concretos de escória ativados por metassilicato de sódio em pó e cal hidratada. Os autores verificaram maior magnitude de retração no concreto de escória $(100 \%$ de escória como aglomerante) álcali ativado quando comparado ao concreto de cimento Portland comum, embora este tenha perdido mais água que aquele durante a secagem ao ar. Collins e Sanjayan (2000) concluíram que a maior retração do concreto de escória álcali ativado não se justifica somente pela quantidade de água perdida durante a secagem, mas também pelo maior percentual de poros na faixa dos mesoporos, uma vez que perdeu muito mais água presente nesses poros que o concreto sem escória. Segundo os autores, seus resultados ratificam a teoria de que as tensões capilares estabelecidas durante a secagem, que são mais intensas com a redução do raio dos poros, influenciam significativamente a retração de concretos de escória.

Perenchio (1997) comenta que se acredita que a retração hidráulica nas idades iniciais é devida, principalmente, à tensão superficial gerada pela saída de água através dos poros capilares da pasta hidratada. $\mathrm{O}$ autor ainda comenta que, em se tratando da retração em idades avançadas, considera-se que é causada pela perda de água adsorvida nas superfícies da pasta de cimento hidratada. Aldred e Lee (2004) afirmam que o mecanismo de tensão capilar é usado para explicar a retração hidráulica.

Conforme Neville (1997), o esvaziamento dos capilares causa uma perda de água sem retração, porém, uma vez removida a água capilar, passa a ocorrer a remoção da água adsorvida. Perenchio (1997), com o fim de comparar diferentes períodos de cura úmida, moldou misturas com relações água/cimento $(\mathrm{a} / \mathrm{c})$ de $0,3,0,4,0,5,0,6$ e 0,7 , e observou, confrontando as misturas curadas durante 3 dias e 7 dias, menor retração nos concretos curados durante o menor período para as misturas com relações a/c 0,5, 0,6 e 0,7. Com exceção da relação a/c 0,7 , constataram-se diferenças pouco expressivas de retração entre os dois períodos de cura.

O emprego de concreto composto com escória ativada (50A) causou uma queda de retração, quando comparado ao concreto correspondente não ativado (50E); essa tendência também foi observada por Mun et al. (2007). Essa constatação pode ser explicada em função do refinamento da estrutura da pasta e redução da conectividade dos poros, comprovados pelos resultados obtidos por Lübeck (2008), que empregou as mesmas misturas do presente estudo e verificou, nos prazos de cura de 3 e 7 dias, aumentos expressivos de resistividade elétrica aparente a partir do uso de ativador químico. Essa justificativa foi considerada porque, de acordo com Andrade (2005), a resistividade elétrica de concreto saturado é uma medida indireta da conectividade dos poros.

As comparações de desempenho, quanto à retração, entre as misturas avaliadas nesta pesquisa foram feitas com base nos resultados de Sivasundaram e Malhotra (1992), que levaram os autores a concluir que a retração foi praticamente a mesma dentro de uma faixa entre 405 e $493 \times 10^{-6}$, ou seja, para uma variação de $22 \%$ entre o menor e o maior dos valores.

\section{Penetração de cloretos por imersão}

Para a análise dos resultados deste ensaio foi usado o coeficiente angular da equação de regressão linear, proposta por Bakker (1988) e empregada por Wee et al. (2000), chamado coeficiente de penetração. A partir de gráficos (profundidade de penetração versus $\sqrt{ }$ tempo) foram obtidas equações de regressão (Equação 1) correspondentes às linhas retas de tendências traçadas entre os pontos obtidos (profundidades de penetração para cada uma das 5 idades) em cada mistura investigada. Das equações foram obtidos os coeficientes de penetração $(\mathrm{k})$ e, das retas de tendências, seus coeficientes de determinação $\left(\mathrm{R}^{2}\right)$.

$\mathrm{y}=\mathrm{k} \cdot\left(V_{\text {semana }}\right)+\mathrm{a}$

A adoção de uma constante "a" igual a zero gera maiores coeficientes de penetração e menores coeficientes de determinação, de modo que impossibilita o melhor ajuste aos resultados obtidos no ensaio, conforme foi comprovado por Siqueira (2008). Assim, a constante "a" foi considerada diferente de zero, como propõem Wee 
et al. (2000), os quais ainda comentam que a magnitude dessa constante se caracteriza mais como um artefato para o ajuste da curva do que como um indicador das propriedades das misturas. Para diferenciar a simbologia, nesse método $(a \neq 0)$ o coeficiente de penetração foi denominado k'.

Constata-se, a partir da análise da Figura 5 e independentemente do cimento empregado, redução dos coeficientes de penetração de cloretos com o aumento do teor de escória nos concretos, quando comparados aos concretos de referência, em igualdade de cura e relação a/agl, em conformidade com o observado por Wee et al. (2000) e Siqueira (2008). Esse desempenho pode ser explicado pela maior capacidade de fixação dos

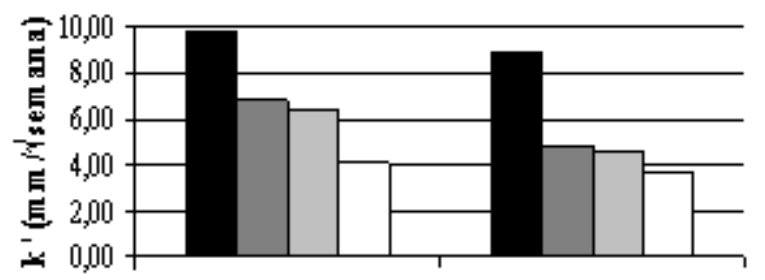

3 dis

7 dias

Cur

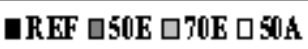

(a) $\mathrm{CPB}$ a/agl $=0,55$

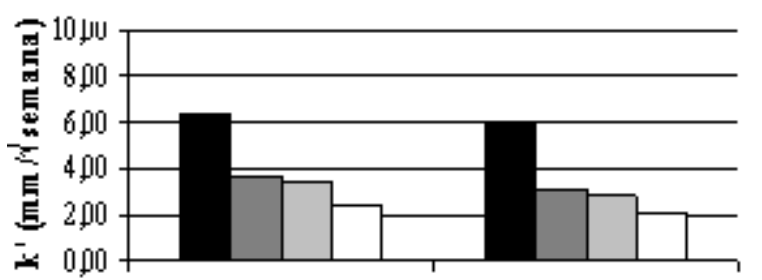

3 dins

7 diss

Cura

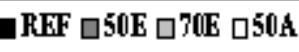

(c) $\mathrm{CPB}$ a/agl $=0,42$

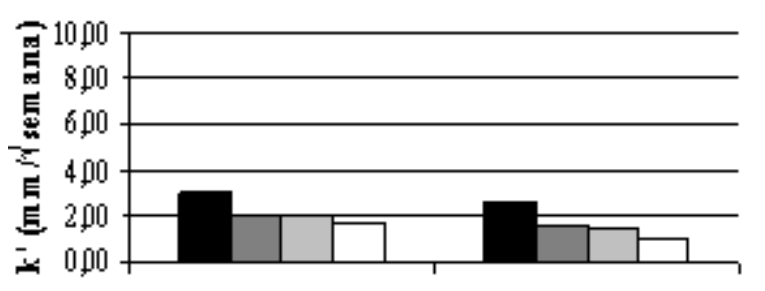

3 dis

7 dis

Cur

口REF Q50E Q70E $\square 50 \mathrm{~A}$

(e) $\mathrm{CPB}$ a/agl=0,30 íons cloretos e de refinamento da estrutura dos poros proporcionados pelo emprego da escória. A tendência de redução do coeficiente de penetração de cloretos a partir do emprego de escória como substituição parcial do cimento Portland no concreto também foi constatada por Chang e Marosszeky (1997) e McGrath e Hooton (1997).

Ao comparar os concretos branco e cinza entre si, observam-se maiores coeficientes de penetração nas misturas moldadas com CPB, em igualdade de relação a/agl, período de cura e teor de escória. Isso pode ser justificado pelos resultados do ensaio de retração hidráulica, a partir dos quais foi constatada maior retração nos concretos brancos.

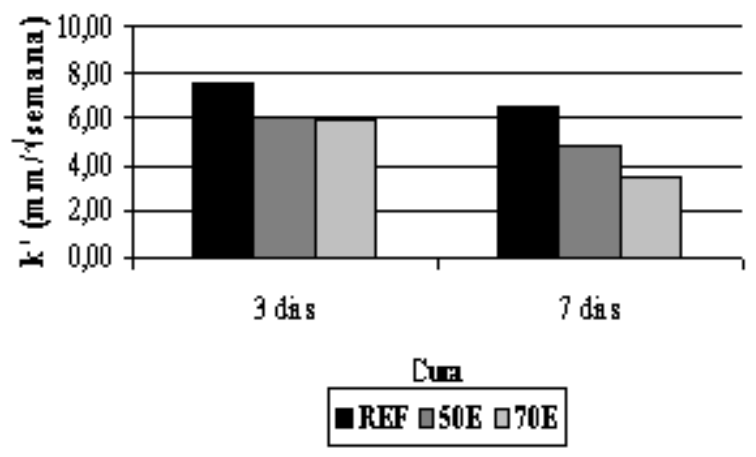

(b) $\mathrm{CPV}$ a/agl=0,55

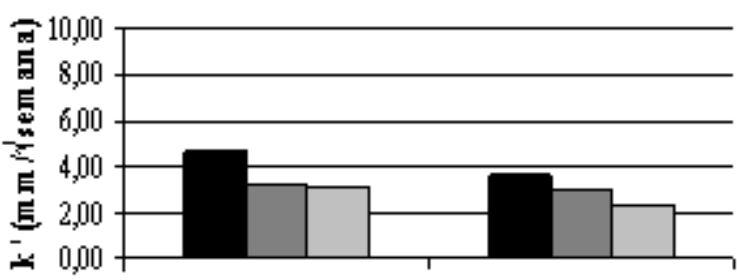

3 disis

7 dis 5

Cur

口REF $\square$ 50E $\square$ TIE

(d) $\mathrm{CPV}$ a/agl=0,42

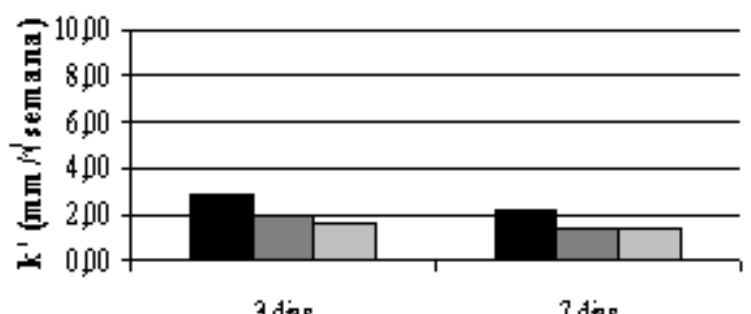

Cura

口 REF प 50E व T0E

(f) $\mathrm{CPV}$ a/agl=0,30

Figura 5 - Coeficientes de penetração de cloretos 
Analisando-se as alterações dos coeficientes de penetração com a variação da relação a/agl em uma mesma mistura, observam-se diferentes desempenhos entre os concretos com escória e o de referência. Neste, os valores dos coeficientes das diferentes relações a/agl apresentaram grandes variações entre si, enquanto a adição de escória gerou uma aproximação entre eles, de modo que essa aproximação foi maior com o aumento do teor de escória, em conformidade com o evidenciado por Siqueira (2008). Na mistura ativada, 50A, foram observadas as maiores aproximações entre os resultados.

$\mathrm{O}$ fato de os corpos de prova terem sido expostos à secagem ao ar durante 91 dias antes de serem colocados na solução salina resultou em coeficientes de penetração elevados, comparados aos coeficientes de Siqueira (2008), que submeteu suas amostras à solução salina logo após saírem da cura. Esse desempenho pode ser justificado pela considerada retração que já havia se desenvolvido nas amostras do presente estudo, a qual as proporcionou faces porosas e suscetíveis à penetração dos íons cloretos, facilitando sua difusão.

\section{Resistência à compressão axial}

Os resultados do ensaio de resistência à compressão axial, em todas as idades de ensaio para todas as misturas, são apresentados na Figura 6.

A partir da análise da Figura 6, verifica-se que o emprego de escória no concreto reduziu sua resistência à compressão axial em todas as idades e relações a/agl avaliadas, de modo que os menores valores foram observados em períodos de cura reduzidos (3 e 7 dias) e no maior teor de substituição (70\%), uma vez que a reação pozolânica é lenta e altamente dependente da formação do hidróxido de cálcio. Esse comportamento também foi evidenciado por Sakai et al. (1992). Dessa maneira, o melhor desempenho entre os concretos de escória foi observado nas misturas 50E, com ambos os cimentos, tendo apresentado as menores reduções de resistência quando comparadas às misturas de referência. Conforme esperado, os piores desempenhos foram evidenciados nas misturas $70 \mathrm{E}$, aos 3 dias e relação a/agl de 0,55 , obtendo apenas $25 \%$ e $28 \%$ da resistência desenvolvida por

seus correspondentes concretos referência branco e cinza.

Ao utilizar o cimento Portland comum existe a tendência de que concretos com escória, num teor de aproximadamente 50\%, superem a resistência do concreto de referência a partir dos 28 dias, conforme evidenciado por Tazawa et al. (1989) e Brooks et al. (1992). Em alguns estudos, como o de Lim e Wee (2000), isso já é evidenciado aos 7 dias.

Comparando-se as misturas de referência branca e cinza entre si, evidenciam-se no concreto cinza, de maneira geral, valores de resistência à compressão ligeiramente superiores. Este comportamento também foi observado por Kirchheim (2003) e Silva et al. (2005), que avaliaram os desempenhos de mais de um tipo de cimento branco estrutural em comparação ao CPVARI.

Considerando-se o concreto de escória com ativador (50A), moldado apenas com cimento branco, observa-se grande melhora de desempenho principalmente até os 28 dias, de modo que apresentou, em praticamente todas as idades e relações a/agl, maiores resistências quando comparado ao concreto 50E. Essa melhora foi ainda mais perceptível na relação a/agl 0,42, aos 7 dias e 28dias, e na relação a/agl 0,55 aos 7 dias, pois nestas misturas o concreto $50 \mathrm{~A}$ superou a resistência das misturas de referência correspondentes. Este benefício, gerado a partir do uso do concreto 50A, ocorre porque as adições alcalinas ativam os materiais acelerando as reações pozolânicas, proporcionando um desenvolvimento de resistência mais rápido (JOHN, 1995). Shi e Day (2000) relatam aumento do $\mathrm{pH}$ da solução devido à presença do ativador químico (Na2SO4) e o efeito benéfico na dissolução de $\mathrm{SiO} 2$ amorfo. Rosa (2005) empregou o mesmo teor de escória e de sulfato de sódio em uma de suas misturas, juntamente com CPV-ARI, e constatou tendências similares.

\section{Conclusões}

Foram obtidos maiores valores de retração total nos concretos moldados com cimento Portland branco, quando comparados ao cinza, inclusive nas misturas compostas com escória, em igualdade de cura e relação a/agl. De maneira geral, independentemente do cimento empregado, embora tenham sido observados valores de retração pouco maiores para a cura de 3 dias, não foi constatada variação expressiva entre os prazos de cura, caracterizando, assim, comportamentos similares. Essas constatações reforçam a teoria da tensão capilar, a qual se processa durante a exposição ao ar, ocasionando ou não retração, o que depende da distribuição dos tamanhos dos poros e também da quantidade de água evaporável. Estas, por sua vez, são influenciadas pelo grau de hidratação do material aglomerante. 
Com relação ao ensaio de penetração de cloretos por imersão, observou-se que o uso de escória juntamente com o cimento Portland favoreceu a resistência à penetração, que aumentou com o acréscimo do teor de escória, ratificando tal efeito, já verificado em outros estudos. No que tange aos prazos de cura, perceberam-se maiores coeficientes de penetração nos concretos curados durante 3 dias, comportamento também observado em outras pesquisas.

A utilização de ativador no concreto gerou reduções satisfatórias dos coeficientes de penetração, pois a mistura $50 \mathrm{~A}$ foi a que apresentou os menores valores. Pelo fato de as amostras terem sido submetidas a um período de

CPB $\mathrm{a} / \mathrm{ag}=0,30$

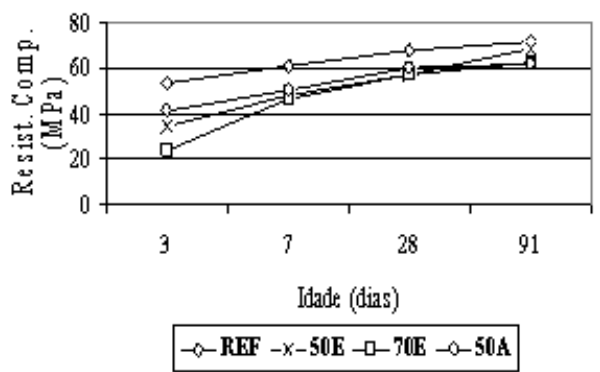

(a) $\mathrm{CPB}$ a agl=0,30

(PB a/ag $=0,42$

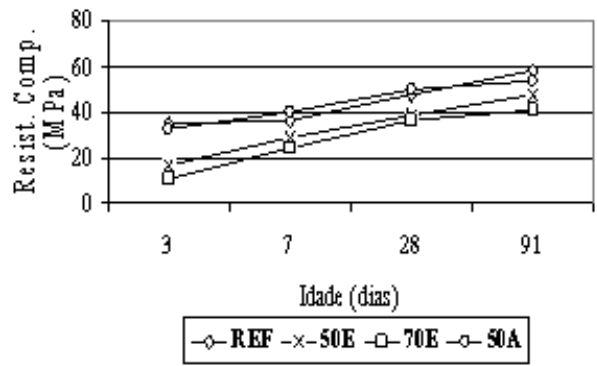

(c) $\mathrm{CPB}$ a $/ \mathrm{agl}=0,42$

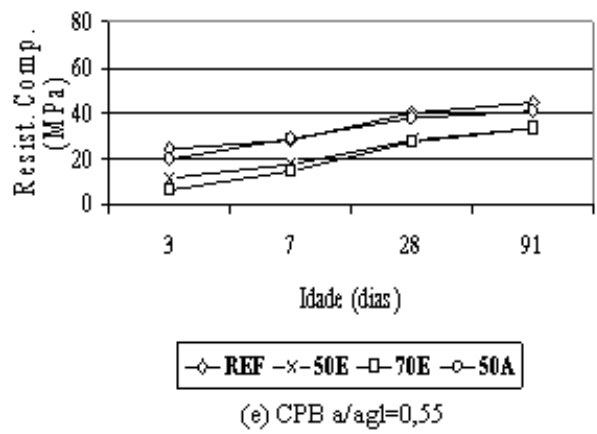

(e) $\mathrm{CPB}$ a $/ \mathrm{ag}=0,55$ exposição ao ar de 91 dias antes da imersão em solução salina, elas já haviam sofrido a maior parte da retração registrada, de modo que foram constatadas profundidades de penetração de cloretos bastante elevadas.

Embora não tenha sido verificada redução expressiva de retração com o aumento do prazo de cura, na penetração de cloretos o concreto de melhor desempenho foi aquele curado durante o maior período, 7 dias. Isso ocorreu porque, além do volume total de poros, distribuição de seus tamanhos e sua interconexão, na retração total o que mais influencia sua magnitude é a quantidade de água evaporada através dos mesoporos.

$(P V$ a/agk $=0,30$

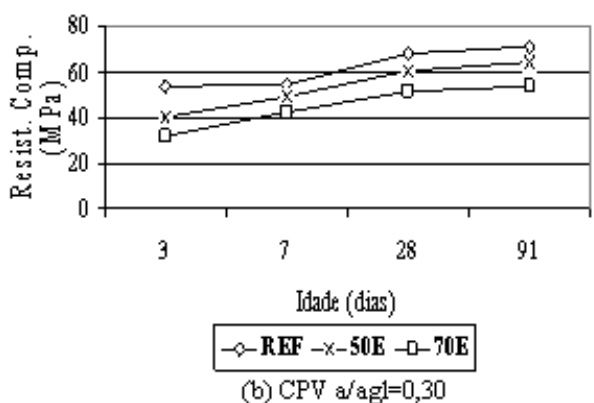

(PV a/agk 0,42
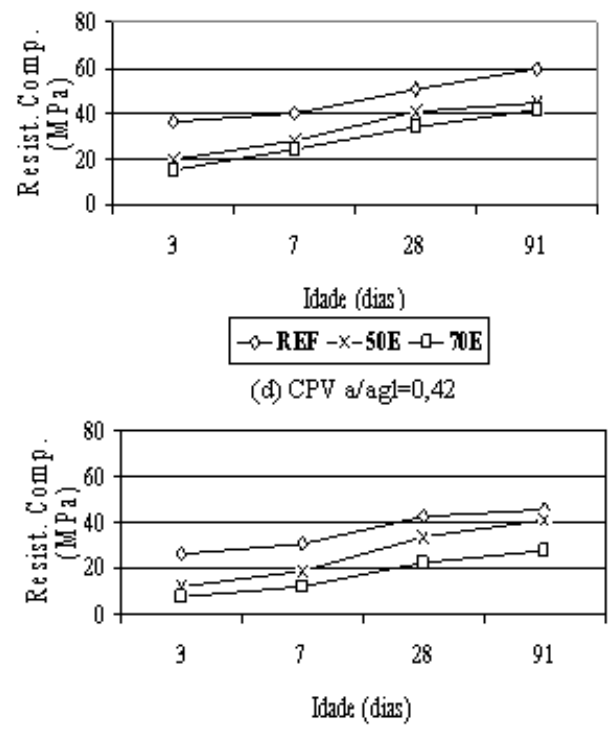

- - REF $-x-50 \mathrm{E}-\square-70 \mathrm{E}$

(f) $\mathrm{CPV}$ a/agl $=0,55$

Figura 6 - Resistências médias de compressão axial 
Foi constatada redução de resistência à compressão axial a partir do emprego de escória. Os menores valores de resistência foram evidenciados na mistura 70E, na qual se observaram, aos 3 e 7 dias, as reduções mais expressivas. Isso se deve ao fato de que a reação pozolânica é lenta e depende da formação de hidróxido de cálcio para formar produtos resistentes.

O emprego de ativador químico mostrou-se vantajoso para atenuar a queda de resistência no concreto com $50 \%$ de escória em substituição ao cimento Portland. Esse artifício resultou em incremento acentuado de resistência nas idades iniciais. Em alguns casos, a resistência do concreto com escória ativada superou, inclusive, as resistências do concreto de referência. Visando à obtenção de elevados desempenhos nas idades iniciais, recomenda-se o emprego da escória de alto-forno ativada quimicamente, desde que os agregados não sejam reativos.

Ao comparar os concretos de referência branco e cinza entre si, observaram-se resistências pouco maiores por parte do cinza, conforme evidenciado em outras pesquisas.

De acordo com os resultados obtidos nos ensaios realizados, conclui-se que a mistura de melhor desempenho, quanto à durabilidade, é a $50 \mathrm{E} \mathrm{CPV}$, a/agl 0,30 e cura de 7 dias, pois apresentou resistência à penetração de cloretos e retração praticamente similares às da mistura $70 \mathrm{E} C P V$ correspondente, além de ter gerado resistências à compressão superiores, quando comparadas as misturas entre si.

\section{Referências}

\section{ASSOCIAÇÃO BRASILEIRA DE NORMAS TÉCNICAS. NBR NM 3: cimento Portland}

Branco: índice de brancura. Rio de Janeiro, 2000.

\section{ASSOCIAÇÃO BRASILEIRA DE NORMAS}

TÉCNICAS. NBR 5739: ensaio de compressão de corpos-de-prova cilíndricos. Rio de Janeiro, 2007.

ALDEA, C. M. et al. Effects of Curing Conditions on Properties of Concrete Using Slag

Replacement. Cement and Concrete Research, v. 30, n. 3, p. 465-472, mar. 2000.

ALDRED, J. M.; LEE, S. N. Factors Affecting the Autogenous Shrinkage of Ground Granulated Blast-Furnace Slag Cement Concrete. In: FLY ASH, SILICA FUME, SLAG AND NATURAL POZZOLANS IN CONCRETE. ACI INTERNATIONAL CONFERENCE, 8., Las Vegas, 2004. Proceedings... Farmington Hills: American Concrete Institute, 2004. p. 783-796.
AMERICAN CONCRETE INSTITUTE. ACI

Committee 209: Report on factors affecting shrinkage and creep of hardened concrete, 2005.

\section{AMERICAN CONCRETE INSTITUTE. ACI}

Committee 222: corrosion of metals in concrete, 2001.

\section{AMERICAN CONCRETE INSTITUTE. ACI}

Committee 233: ground granulated blast-furnace slag as a cementitious constituent in concrete, 2005.

\section{AMERICAN SOCIETY FOR TESTING AND MATERIALS. ASTM C-157/C 157M: standard test method for length change of hardened hydraulic-cement mortar and concrete, 2006.}

\section{AMERICAN SOCIETY FOR TESTING AND} MATERIALS. ASTM C-490: standard practice for use of apparatus for the determination of length change of hardened cement paste, mortar and concrete, 2004.

ANDRADE, C. Model for Prediction of Reinforced Concrete Service Life Based on Electrical Resistivity. Revista IBRACON de Materiais, v. 1, n. 1, p. 1-5, 2005.

ATIS, C. D. et al. ÇELIK, Ö.; KARAHAN, O. Influence of Activator on the Strength and Drying Shrinkage of Alkali-Activated Slag Mortar.

Construction and Building Materials, v. 23, n. 1, p. 548-555, jan. 2009.

BAKHAREV, T. et al. Effect of Elevated Temperature Curing on Properties of AlkaliActivated Slag Concrete. Cement and Concrete Research, v. 29, n. 10, p. 1619-1625, out. 1999.

BAKKER, R. F. M. Corrosion of Steel in Concrete. Paris: RILEM, 1988.

BROOKS, J. J.; WAINWRIGHT, P. J.; BOUKENDAKJI, M. Influence of Slag Type and Replacement Level on Strength, Elasticity, Shrinkage and Creep of Concrete. In: FLY ASH, SILICA FUME, SLAG AND NATURAL POZZOLANS IN CONCRETE. ACI INTERNATIONAL CONFERENCE, 4., Istanbul, 1992. Proceedings... Detroit: American Concrete Institute, 1992. p. 1325-1342. 
CHANG, Z. T.; MAROSSZEKY, M. Chloride Penetration and Water Absorption into P. C.: fly ash and slag concrete under different curing conditions. In: DURABILITY OF CONCRETE. CANMET/ACI INTERNATIONAL CONFERENCE, 4., Sydney, 1997. Proceedings... Farmington Hills: American Concrete Institute, 1997. p. 349-362.

CHERN, J. C.; CHAN, Y. W. Effect of Temperature and Humidity Conditions on the Strength of Blast Furnace Slag Cement Concrete. In: FLY ASH, SILICA FUME, SLAG AND NATURAL POZZOLANS IN CONCRETE. ACI INTERNATIONAL CONFERENCE, 3., Trondheim, 1989. Proceedings... Detroit: American Concrete Institute, 1989. p. 1377-1397.

COLLINS, F.; SANJAYAN, J. G. Effect of Pore size Distribution on Drying Shrinkage of AlkaliActivated Slag Concrete. Cement and Concrete Research, v. 30, n. 9, p. 1401-1406, set. 2000.

GASTALDINI, A. L. G.; et al. Chloride Penetration and Carbonation in Concrete with Rice Husk Ash and Chemical Activators. Cement and Concrete Composites, v. 29, n. 3, p. 176-180, mar. 2007.

GOMES, N. S. Influência de Ativadores Químicos e de Adições Minerais no Comportamento de Concretos Frente a Cloretos. Santa Maria, 2003. Dissertação (Mestrado em Engenharia Civil) - Universidade Federal de Santa Maria, Santa Maria, 2003.

JOHN, V. M. Cimentos de Escória Ativada com Silicato de Sódio. 1995. 190 f. Tese (Doutorado em Engenharia Civil) - Escola Politécnica da Universidade de São Paulo, São Paulo, 1995.

KIRCHHEIM, A. P. Concreto de Cimento Portland Branco Estrutural: avaliação da carbonatação e absorção capilar. 2003. Dissertação (Mestrado em Engenharia Civil) - Universidade Federal do Rio Grande do Sul, Porto Alegre, 2003.

LIM, S. N.; WEE, T. H. Autogenous Shrinkage of Ground-Granulated Blast-Furnace Slag Concrete. ACI Materials Journal, v. 97, n. 5, p. 587-593, set./out. 2000.

LÜBECK, A. Resistividade Elétrica de Concretos de Cimento Portland Branco e Elevados Teores de Escória de Alto-Forno. Santa Maria, 2008. Dissertação (Mestrado em Engenharia Civil) - Universidade Federal de Santa Maria, Santa Maria, 2008.
LUO, R. et al. Study of Chloride Binding and Diffusion in GGBS Concrete. Cement and

Concrete Research, v. 33, n. 1, p. 1-7, jan. 2003.

MCGRATH, P. F.; HOOTON, R. D. Influence of Binder Composition on Chloride Penetration Resistance of Concrete. In: DURABILITY OF CONCRETE. CANMET/ACI INTERNATIONAL CONFERENCE, 4., Sydney, 1997. Proceedings... Farmington Hills: American Concrete Institute, 1997. p. 331-347.

MEHTA, P. K.; MONTEIRO, P. J. M. Concreto: estrutura, propriedades e materiais. São Paulo: PINI, 2008.

MOHAMMED, T.U.; YAMAJI, T.; HAMADA, H. Chloride Diffusion, Microestructure, and Mineralogy of Concrete After 15 Years of Exposure in Tidal Environment. ACI Materials Journal, v. 99, n. 3, p. 256-263, maio/jun. 2002.

MUN, K. J.; SO, S. Y.; SOH, Y.S. The Effect of Slaked Lime, Anhydrous Gypsum and Limestone Powder on Properties of Blast Furnace Slag Cement Mortar and Concrete. Construction and Building Materials, v. 21, n. 7, p. 1576-1582, jul. 2007.

NAKAMURA, N.; SAKI, M.; SWAMY, R. N. Effect of Slag Fineness on the Development of Concrete Strength and Microstructure. In: FLY ASH, SILICA FUME, SLAG AND NATURALS POZZOLANS IN CONCRETE. ACI

INTERNATIONAL CONFERENCE, 4., Istanbul, 1992. Proceedings. Detroit: American Concrete Institute, 1992. p. 1343-1366.

NEVILLE, A. M. Propriedades do Concreto. Tradução: Salvador E. Giammusso. São Paulo: PINI, 1997.

PERENCHIO, W. F. The Drying Shrinkage Dilemma. Concrete Construction, v. 42, n. 4, p. 379-383, abr. 1997.

ROSA, D. W. Resistividade Elétrica de Concretos com Diferentes Teores de Escória de Alto-Forno e Ativador Químico. 2005. Dissertação (Mestrado em Engenharia Civil) Universidade Federal de Santa Maria, Santa Maria, 2005. 
SAKAI, K. et al. Properties of Granulated BlastFurnace Slag Cement Concrete. In: FLY ASH, SILICA FUME, SLAG AND NATURAL POZZOLANS IN CONCRETE. ACI INTERNATIONAL CONFERENCE, 4., Istanbul, 1992. Proceedings. Detroit: American Concrete Institute, 1992. p. 1367-1383.

SCHNEIDER, J. A. et al. Avaliação da Penetração de Cloretos em Concreto com Escória de AltoForno e Ativador Químico Imersos em Solução Salina. In: JORNADAS SUDAMERICANAS DE INGENIERÍA ESTRUCTURAL, 33., 2008, Santiago de Chile. Anais... Santiago de Chile: Universidad Central, 2008. v. 1, p. 1-18.

SHI, C.; DAY, R. L. Pozzolanic Reaction in the Presence of Chemical Activators: part II, reaction products and mechanism. Cement and Concrete Research, v. 30, n. 4, p. 607-613, abr. 2000.

SILVA, L. B. et al. Estudo da Absorção Capilar em Concretos Brancos. In: CONGRESSO BRASILEIRO DO CONCRETO, 47., 2005, Recife. Anais... São Paulo: Instituto Brasileiro do Concreto, 2005.

SIQUEIRA, H. C. Penetração de Cloretos em Concretos Compostos com Cimento Portland Branco e Escória de Alto-Forno, Ativados Quimicamente. 2008. Dissertação (Mestrado em Engenharia Civil) - Escola de Engenharia, Universidade Federal de Santa Maria, Santa Maria, 2008.

SIVASUNDARAM, V.; MALHOTRA, V. M. Properties of Concrete Incorporating Low Quantity of Cement and High Volumes of Ground Granulated Slag. ACI Materials Journal, v. 89, n. 6, p. 554-563, nov./dez. 1992.
SUZUKI, K.; OHNO, Y.; NAKAGAWA, T. Test Method for Cracking of Concrete Due to Drying Shrinkage. In: CREEP AND SHRINKAGE OF CONCRETE. RILEM INTERNATIONAL SYMPOSIUM, 5., Barcelona, 1993. Proceedings... Londres: E\&FN SPON, 1993. p. $63-70$.

TAZAWA, E.; YONEKURA, A.; TANAKA, S. Drying Shrinkage and Creep of Concrete Containing Granulated Blast Furnace Slag. In: FLY ASH, SILICA FUME, SLAG AND NATURAL POZZOLANS IN CONCRETE. ACI INTERNATIONAL CONFERENCE, 3., Trondheim, 1989. Proceedings... Detroit: American Concrete Institute, 1989. p. 1325-1343.

WEE, T. H.; SURYAVANSHI, A. K.; TIN, S. S. Evaluation of Rapid Chloride Permeability Test (RCPT) Results for Concrete Containing Mineral Admixtures. ACI Materials Journal, v. 97, n. 2, p. 221-232, mar./abr. 2000.

YOUNG, J. F. Physical Mechanisms and Their Mathematical Descriptions. In: BAZANT, Z. P. Bazant (Ed.). Mathematical Modeling of Creep and Shrinkage of Concrete. Wiley, 1988. p. 63-98.

ZHANG, M. H. et al. Concrete Incorporating Supplementary Cementing Materials: effect of curing on compressive strength and resistance to chloride-ion penetration. ACI Materials Journal, v. 96, n. 2, p. 181-189, mar./abr. 1999.

ZIA, P.; AHMAD, S.; LEMING, M. High-

Performance Concretes: a state-of-art. Report (1989-1994) FHWA-RD-97-030, Federal Highway Administration, Department of Transportation, Washington, 1997.

\section{Agradecimentos}

Os autores agradecem aos alunos bolsistas de iniciação científica do GEPECON pela ajuda nos ensaios; ao CNPq, CAPES e FAPERGS pelos recursos e bolsas concedidos; e às empresas Cimento Mizu, Camargo Correa e BASF pelos materiais cedidos. 